Ocean Engineering

June 2015, Volume 101 Pages 142-151

http://dx.doi.org/10.1016/i.oceaneng.2015.04.027

http://archimer.ifremer.fr/doc/00266/37710/

(c) 2015 Elsevier Ltd. All rights reserved.

\title{
The effect of the bottom boundary layer on trawl behaviour
}

\author{
de la Prada Amelia ${ }^{1,{ }^{*}}$, Priour Daniel ${ }^{2}$ \\ ${ }^{1}$ University of A Coruña, Laboratorio de Ingeniería Mecánica, 15403 Ferrol, Spain \\ 2 Ifremer, BP 70, 29280 Plouzané, France \\ * Corresponding author: Amelia de la Prada, Tel.: +34 654492613 ; \\ email address : amelia.delaprada@udc.es \\ daniel.priour@ifremer.fr
}

\begin{abstract}
:
Thirty-seven hauls of a bottom trawl were carried out, as part of a national French project. These sea trials were undertaken in an area with strong currents: up to 1 knot. The measurements at sea of the bottom bridle's tension show a clear effect of the current. Although the water speed relative to the trawl is constant, when the boat tows with current, the bottom bridle's tension increases, and when the boat tows against the current, the bottom bridle's tension decreases. The mean bottom bridle tension is 7840 $\mathrm{N}$ and increases with a slope of $1197 \mathrm{~N}$ for each $\mathrm{m} / \mathrm{s}$ of current. The current has almost no effect on the top bridle's tension: for a mean value of approximately $9810 \mathrm{~N}$, the increment is $106 \mathrm{~N}$ for each m/s of current. The modelling of the trawl gear and the boundary layer explains this behaviour. Boundary layers of different thicknesses have been simulated. A boundary layer of $0.9 \mathrm{~m}$ height shows the best fit between simulation and measurements. The simulated bottom bridle's tension increases to $1343 \mathrm{~N}$ each $\mathrm{m} / \mathrm{s}$ of current while the top bridle's tension decreases to $320 \mathrm{~N}$ each $\mathrm{m} / \mathrm{s}$. These values are inside the standard deviation of the measurements.
\end{abstract}

\section{Highlights}

- Measurements at sea of a bottom trawl behaviour. Measurements show that the tension in top and bottom bridles is affected by the relative water speed profile. Modeling of the bottom trawl with FEM. Incorporation of the bottom boundary layer to the numerical model. Numerical results fit pretty well with the measurements.

Keywords : Trawl, Data, Numerical model, Bridle tension, Bottom boundary layer, Water speed 


\section{Nomenclature}

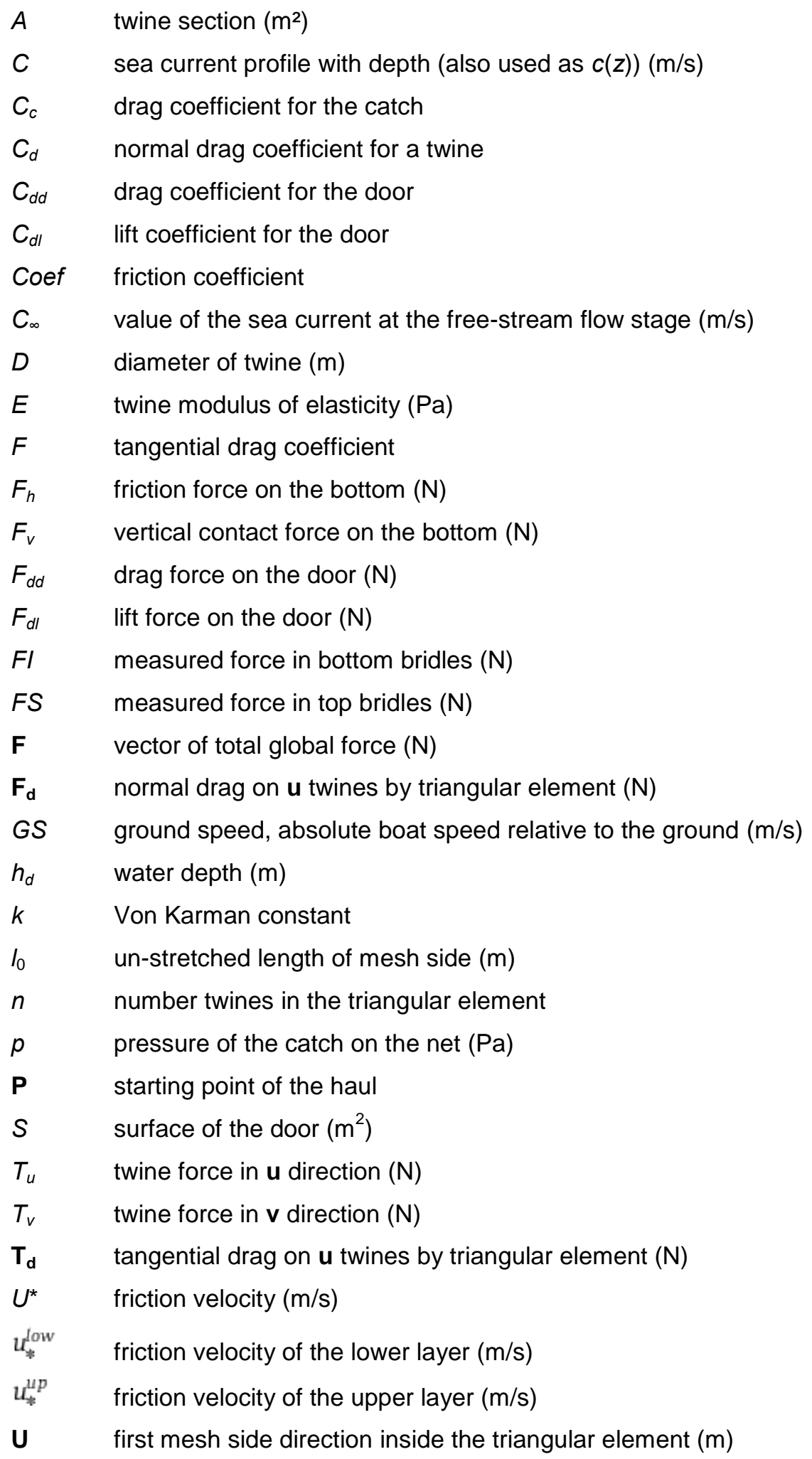


$V_{c} \quad$ fluid velocity relative to the catch $(\mathrm{m} / \mathrm{s})$

V second mesh side direction inside the triangular element $(\mathrm{m})$

V water speed relative to the twine, that is, the ws profile $(\mathrm{m} / \mathrm{s})$

$\mathbf{V}_{\mathbf{d}} \quad$ water speed relative to the door $(\mathrm{m} / \mathrm{s})$

Ws water relative velocity profile with depth $(\mathrm{m} / \mathrm{s})$

WS water speed, measured value of the water relative velocity $(\mathrm{m} / \mathrm{s})$

$\mathbf{X} \quad$ vector of global coordinates $(\mathrm{m})$

$\mathbf{X}_{\text {final }} \quad$ vector of coordinates at the equilibrium position $(\mathrm{m})$

$X_{\text {initial }} \quad$ vector of initial coordinates $(m)$

$Z \quad$ depth $(m)$

$z_{0} \quad$ roughness length $(\mathrm{cm})$

$z_{0}^{\text {bow }} \quad$ roughness length of the lower layer $(\mathrm{cm})$

$z_{0}^{u p} \quad$ roughness length of the upper layer $(\mathrm{cm})$

A angle between the $\mathbf{u}$ vector and the water velocity $\mathbf{V}$ (radians)

$P \quad$ density of water $\left(1025 \mathrm{~kg} / \mathrm{m}^{3}\right.$ in the present study)

\section{Introduction}

During the last couple of years numerous studies on fuel efficiency of fishing gear have been carried out following the large increase in energy costs. One of them, the French 
EFFICHALUT project (Priour, 2012), were dedicated to enhancing the energy efficiency of

76 bottom trawl. The main result of this project was a new design of the top wings which has

77 lead to an improvement of $17 \%$ of the energy efficiency. During this project numerous

78 measurements were carried out and analyzed at sea on the bottom trawl but some findings

79 were not described since they were outside the aim of the project. The sea trials have been

80 carried out in zones with quite large currents: up to $1 \mathrm{knot}$. The current is associated with

81 boundary layer, which is defined as a gradient of water speed close to the bottom. In this

82 paper we intend to analyse the effect of boundary layer on gear geometry behaviour.

83 As far as we know, there are no studies of the effect of boundary layer on trawl behaviour.

84 Only a few studies have been carried out on current effect: Weinberg (et al. 2002) and

85 Somerton (et al., 2001) have shown that current can affect the ability to catch fish. Coles

86 (1979) has demonstrated the effect of tidal current on trawl catch. Net spread is also a

87 function of bottom currents and tow direction relative to currents (von Szalay et al. 2005).

88 Trawl performance is, generally speaking, researched using flume tank tests (Ward et

89 al.,1993, Ferro et al., 1996), full scale tests at sea (Sala et al., 2011), analytical modelling

90 (Park, 2007), or numerical modelling (Lee et al., 2005, Takagi et al., 2003, Tsukrov et al.,

91 2003, Priour, 2003 and 2013a). These investigations take into account the design of the gear,

92 the mean water speed, and the bottom contact. However, there are not studies on boundary

93 layer effect in the bibliography.

94 Therefore, the aim of this work is to analyse the effect of the boundary layer on the trawl

95 behaviour by using the real measurements at sea from the EFFICHALUT project. Also, these

96 measurements are compared with the solution obtained by a numerical model in order to

97 validate it. Note that a study on the catch effect on the trawl geometry has already been done

98 using the same data (Priour, 2013b). 
101 4. Materials and methods

102 4.1. Trial tests

103 Test at sea were carried out in April 2010. During two weeks 37 hauls were made with a

104 bottom trawl. The drawings of the trawl are provided in Figure 1. Figure 2 shows a schema of 105 the rigging for half trawl, it presents the wire configuration and the doors, with the 106 components marked with labels. The doors, from Morgere company (Oval Foil model), were $1072.9 \mathrm{~m} \times 1.85 \mathrm{~m}$ wide and weigh $1.4 \mathrm{t}$. The warp length was approximately three times the 108 water depth, that is, $150 \mathrm{~m}$ for the first week at sea and $60 \mathrm{~m}$ for the second, as the depths 109 were $50 \mathrm{~m}$ and $20 \mathrm{~m}$, respectively. The main fish species were mackerel, whiting, gurnet, 110 gurnard, horse mackerel, and sea-bass. The fisherman drove the trawl at a constant engine 111 power (107 l/h of fuel).

112 The trawl was equipped with six tension sensors, which were located on each bottom bridle, 113 top bridle and warp (Figure 3). The tensions were recorded by NKE SF sensors (range 5 ton, 114 accuracy $25 \mathrm{~kg}$ and resolution $2.2 \mathrm{~kg}$ ). The depth, height and the spread of the doors were also 115 recorded (heel and trim). The sensors used were NKE S3AP sensors for the door's height and 116 SCANMAR sensors for the door's spread. The water speed relative to the headline (called 117 water speed, WS) and the vertical opening were measured with SCANMAR sensors fastened 118 to the headline of the trawl. The absolute towing speed, that is, relative to the ground (also 119 called ground speed, GS), was measured with a GPS. More information about the 120 measurements can be found in a previous work (Priour, 2013b). Unfortunately, no samples of 121 type and disposition of soil and were taken, which limits the experimental validation of this 122 work. 
126 The numerical model has already been used in previous works. In this paper, only a general

127 view is described. More detailed information can be found in the previous bibliography

128 (Priour, 2013a and 2013b).

129 The model is based on the Finite Element Method (FEM). Linear bar elements are used to

130 model the warps, bridles and cables, while the net is discretized into finite triangular elements.

131 Through its three nodes (placed on its vertices), the triangular element has equivalent 132 behaviour to the net material, since two directions are defined: $\mathbf{u}$ and $\mathbf{v}$ for diamond and 133 square meshes (three for hexagonal meshes). The element is able to cover a large number of 134 meshes.

135 Inside the element, each twine direction is kept parallel, leading to a constant deformation for 136 all the $\mathbf{u}$ twines, as well as the $\mathbf{v}$ twines. Obviously there is a variation of orientation and 137 deformation from one triangular element to an adjacent one; this hypothesis is reasonable if 138 elements are small. With the previous hypotheses, the forces on each element can be 139 calculated. These forces depend on the position of the nodes.

\section{0 i) Elastic forces in twines}

141 The twines are modelled as linear springs. Their tensions $T_{u}$ and $T_{v}$ are calculated with

142 Equations 1 and 2. In order to make the twine model more realistic, compression tensions are 143 cancelled, by supposing different elastic modulus when the twine is stretched (taken from the 144 material properties) than it is un-stretched (considered a very low value or zero).

$145 T_{u}=E A \frac{|\mathbf{u}|-l_{0}}{l_{0}}$

$146 T_{v}=E A \frac{|\mathbf{v}|-l_{0}}{l_{0}}$ 
147 Where $E$ is the twine modulus of elasticity, $A$ is the twine section , $l_{0}$ is the un-stretched

148 length of mesh side , and $|\mathbf{u}|(|\mathbf{v}|)$ is the stretched length of mesh side along $\mathbf{u}(\mathbf{v})$ direction.

149 With the coordinates of the vertices of the triangular element, the vectors $\mathbf{u}$ and $\mathbf{v}$ and the

150 number of meshes, the forces applied on the vertices (nodes) are equivalent to the tension of

151 all twines of a triangle. The development and the expressions are shown in Priour 2013a.

152 ii) Hydrodynamic drag

153 As explained before, the drag force on the netting is calculated in this model as the sum of the

154 drag force on each twine ( $\mathbf{u}$ and $\mathbf{v}$ ). The amplitude of hydrodynamic forces for a twine are

155 evaluated according to Equations 3 and 4. The direction of the forces can also be evaluated

156 (Equations 5 and 6) because each pair of twine vectors, $\mathbf{u}$ and $\mathbf{v}$, is known. The following

157 equations for the normal $\mathbf{F}_{\mathbf{d}}$ and tangential drag $\mathbf{T}_{\mathbf{d}}$ are only presented for the $\mathbf{u}$ twines, but the

158 expressions for $\mathbf{v}$ twines can be inferred similarly:

$\left|\mathbf{F}_{\mathbf{d}}\right|=\frac{1}{2} \rho C_{d} D l_{0}(|\mathbf{V}| \sin (\alpha))^{2} \frac{n}{2}$

160

$\left|\mathbf{T}_{\mathbf{d}}\right|=\frac{1}{2} f \rho C_{d} D l_{0}(|\mathbf{V}| \cos (\alpha))^{2} \frac{n}{2}$

$161 \quad \frac{\mathbf{F}_{\mathbf{d}}}{\left|\mathbf{F}_{\mathbf{d}}\right|}=\frac{\mathbf{u} \wedge(\mathbf{V} \wedge \mathbf{u})}{|\mathbf{u} \wedge(\mathbf{V} \wedge \mathbf{u})|}$

$162 \frac{\mathbf{T}_{\mathbf{d}}}{\left|\mathbf{T}_{\mathbf{d}}\right|}=\frac{\mathbf{F}_{\mathbf{d}} \wedge\left(\mathbf{V} \wedge \mathbf{F}_{\mathbf{d}}\right)}{\left|\mathbf{F}_{\mathbf{d}} \wedge\left(\mathbf{V} \wedge \mathbf{F}_{\mathbf{d}}\right)\right|}$

163 Where $\mathbf{V}$ is the water speed relative to the twine, that is, the ws profile, $\rho$ is the density of

164 water $\left(1025 \mathrm{~kg} / \mathrm{m}^{3}\right.$ in the present study), $C_{d}$ is normal drag coefficient for a twine (1.2 in the

165 present study), $f$ is the tangential drag coefficient (0.08 in this work ), $D$ is the diameter of

166 twine, $\alpha$ is the angle between the $\mathbf{u}$ vector and the water velocity $\mathbf{V}$, and $n / 2$ the number of $\mathbf{u}$

167 twine vectors in the triangular element. 
170 The drag caused by the contact with the seabed is due to the friction forces and the resistance

171 of the sediments built up in front of the components that are in contact with the bottom. In this

172 work we assume the approach of modelling both forces together through the well-known

173 Coulomb friction expression, according to Pashen et al. (2000). This is an approximation

174 since it considers that the seabed is a coarse but solid material. In this work the type of soil is 175 not considered since no information about the type of soil was took in the sea trials. The 176 friction coefficient is a mean value estimated by Pashen et al. (2000). However, awareness

177 should be taken in this topic since, according to Ivanović et al., (2011), the friction force can 178 even fourfold depending on the type and disposition (rippled or level) of the soil. A more 179 accurate model based on finite element analysis to predict the deformation of the seabed were 180 developed by Ivanović et al., (2011).

$181 \quad F_{h}=$ Coef $F_{v}$

182 Where $F_{h}$ is friction force on the bottom, $F_{v}$ the vertical contact force on the bottom and Coef

183 is the friction coefficient estimated by Pashen et al. (2000) which encompasses both forces

184 (friction and sediment displacement), the selected value in this work is 1.

185 iv) Fish catch pressure

186 The effect of the caught fish is estimated by a pressure (Priour, 2013a). This pressure $p$ is 187 exerted on the triangular elements in contact with the catch:

$188 p=\frac{1}{2} \rho C_{c}\left|\mathbf{V}_{\mathbf{c}}\right|^{2}$

189 Where $C_{c}$ is the drag coefficient for the catch (1.4 in Priour, 2013a), $\mathbf{V}_{c}$ correspods to the fluid 190 velocity relative to the catch. In this work, the boundary layer is not used to evaluate the 191 pressure of the catch. The applied values in the simulations are the water speed at the headline 192 (WS). According to the table of the drag repartition in Priour (2009), the error introduced with 
193 this approach will not be very considerable since the catch drag represents a $10 \%$ of the total

194 drag.

195 The volume of the catch inside the cod-end used in this work is a mean value assessed by the

196 fisherman and it is $0.74 \mathrm{~m}^{3}$, (more details in Priour, 2013b).

197 v) Doors modelling

198 The doors are modelled as a rectangle whose surface $S$ is $4.5 \mathrm{~m}^{2}$. The applied forces on the 199 doors are the weight (1400 kg), the buoyancy (76 Litre) and the hydrodynamic forces, drag $200\left(F_{d d}\right)$ and lift $\left(F_{d l}\right)$. The values of the drag $\left(C_{d d}\right)$ and lift $\left(C_{d l}\right)$ coefficients are 1.35 and 1.43, 201 respectively, and are provided by the door maker for a mean value of the water speed. In order 202 to simplify the model, we do not consider the boundary layer, we assess that the water speed 203 relative to the door $\left(\mathbf{V}_{\mathrm{d}}\right)$ as constant $\left(\left|\mathbf{V}_{\mathrm{d}}\right|=W S\right)$. We suppose that the error introduced with 204 this hypothesis will not be significant since, according to Priour (2009) the hydrodynamic 205 drag on doors represents a $20 \%$ of the total drag.

$206 \quad F_{d d}=\frac{1}{2} \rho C_{d d} S\left|\mathbf{V}_{\mathbf{d}}\right|^{2}$

$207 \quad F_{d l}=\frac{1}{2} \rho C_{d l} S\left|\mathbf{V}_{\mathbf{d}}\right|^{2}$

208 vi) Sum of forces

209 The forces described previously are calculated for each node. The total load is the sum of all

210 of them, and these forces depend on the node positions $(\mathbf{F}(\mathbf{X}))$. The static equilibrium of the

211 net is reached when $\mathbf{F}\left(\mathbf{X}_{\text {final }}\right)=\mathbf{0}$, forming a non linear system of equations. The initial

212 position $\left(\mathbf{X}_{\text {initial }}\right)$ of the nodes, is arbitrarily defined by the user of the FEM model and usually

213 is not at equilibrium, so $\mathbf{F}\left(\mathbf{X}_{\text {initial }}\right) \neq \mathbf{0}$. In the present work, the well-known Newton Raphson 
214 Method is used to achieve the equilibrium position $\mathbf{X}_{\text {final }}$. Note that this method requires the

215 evaluation of the jacobian matrix (first derivative of the forces) $\mathbf{F}^{\prime}(\mathbf{X})$ at each iteration.

216 4.3. Theoretical models for the boundary layer

217 In this Subsection we would like to describe a general view of the Bottom Boundary Layer

218 (BBL). A further explanation can be found in the bibliography (Soulsby ,1983 and Aoustin, 219 1990) .

220 Close to the seabed, the flow velocity is influenced by the effect of friction. The BBL is the

221 transition flow layer from the seabed to the free-stream flow. In the sea, the BBL is

222 considered always turbulent. It can be divided into three sublayers which are shown in

223 Figure 4, where sea current, $c(z)$, is represented as a function of the depth $z$.

224 The first sublayer is called the bed layer. It is placed very near the bed and it is typically a few

225 centimetres thick. In this layer, either the bed is smooth enough that the effect of molecular 226 viscosity dominates the dynamics, or the presence of rough elements causes variations in the 227 profiles of velocity around them. In this work, the bed layer is considered negligible due to 228 the small thickness (few centimetres) in comparison with the thickness of the other sublayers $229(\approx 10 \mathrm{~m})$.

230 Above this is the logarithmic layer, in which neither the details of the bed nor the free flow 231 affect the local dynamics and it takes a universal turbulent profile. It generally extends to a 232 height of a few meters in the sea.

233 The third sublayer is called the outer layer, in which the velocity and turbulence profiles 234 depend strongly on the nature of the free-stream flow. Consequently, there are a lot of models 235 for the outer layer depending on the different phenomena which govern the free-stream flow 236 at the sea; for example, the tidal oscillation, the earth's rotation, and vertical density gradient. 
237 The outer layer is tens of metres thick. Finally, the free-stream flow stage is reached, where

238 the current velocity is constant $C_{\infty}$.

239 The boundary layer is quite complicated to model, as it depends on several parameters

240 (composition of the soil, viscosity and density of the fluid, fluid velocity...). Although there

241 are a lot of studies in the bibliography which try to fit expressions with real measurements at

242 sea, there is not a general model that can be applied in every situation. Nearly all the models

243 are based on logarithmic expressions where the depth $\mathrm{z}$ is expressed as a function of the fluid

244 velocity $c$. In the present work three models are studied, which are shown in Figure 5:

245 Model no. 1: Logarithmic layer 005 (law-of-the-wall)

246 This is the most common and simple model. This model approximates the fluid velocity $(c)$ in

247 boundary layer with the following equation (Soulsby, 1983 and Aoustin, 1990):

$248 \quad C(z)=\frac{u_{*}}{k} \ln \left(\frac{Z}{Z_{0}}\right)$

249 Where $u_{*}$ is the friction velocity, $k$ the Von Karman constant and $z_{0}$ is the roughness length.

250 The Von Karman constant $k$ is typically 0.4 and a set of values for $z_{0}$ is provided,

251 corresponding to different types of soils, in Soulsby (1983).

252 In this model the friction velocity is dependent on the free-stream flow velocity $\left(C_{\infty}\right)$ :

$253 u_{*}=0.05 C_{\infty}$

254 Model no. 2: Upper and lower layers.

255 Sanford and Lien (1999) divided the boundary layer in two curves. Both curves have the

256 logarithmic shape shown in Equation 11 but the values of the constants are different for the

257 lower log layer and the upper log layer. The curves were fitted with experimental 
258 measurements, resulting in the following values (from Perlin et al. (2005)): $u_{*}^{\text {low }}=0.025 \mathrm{~m} / \mathrm{s}$,

$259 z_{0}^{\text {low }}=0.0002 \mathrm{~m}, u_{*}^{\text {up }}=0.044 \mathrm{~m} / \mathrm{s}$ and $z_{0}^{\text {up }}=0.013 \mathrm{~m}$.

$260 \quad c^{\text {low }}(z)=\frac{u_{*}^{\text {low }}}{k} \ln \frac{z}{z_{0}^{\text {low }}}$

$261 \quad c^{u p}(z)=\frac{u_{*}^{u p}}{k} \ln \frac{z}{z_{0}^{u p}}$

262 This model fits quite well until the depth is $13 \mathrm{~m}$ (where $C_{\infty}$ is approximately $0.76 \mathrm{~m} / \mathrm{s}$ ), but it

263 presents an irregularity at the crossing point between the lower layer and the upper log layer

264 (at $0.6 \mathrm{~m} / \mathrm{s}$ in Figure 5 ).

265 Model no. 3: Modified law-of-wall.

266 Perlin et al. (2005) developed a new expression in order to unify the upper and lower curves

267 developed by Sanford and Lien (1999) and therefore overcome their weakness at the crossing

268 point. The expression was also used to fit experimental data measured by Perlin et al.(2005)

269 as well as data from other authors (particularly from Sanford and Lien (1999)).

$270 \quad C(z)=\frac{u_{*}}{k} \ln \left(\frac{z\left(h_{d}-z_{0}\right)}{z_{0}\left(h_{d}-z\right)}\right)$

271 Where $h_{d}$ is the water depth (calibration values obtained by Perlin et al. (2005) for

272 measurements from Sanford and Lien (1999) $h_{d}=23 \mathrm{~m}, z_{0}=0.0006 \mathrm{~m}, u_{*}=0.028 \mathrm{~m} / \mathrm{s}$ ).

273

274 Figure 5 shows a comparison of the three models. The three models are quite similar and

275 cross $\mathrm{C}_{\infty}$ at about 13-14 $\mathrm{m}$. The crossing point can also be observed between lower and upper 276 curves of model no. 2 at around $0.6 \mathrm{~m} / \mathrm{s}$. 
277 The three models have the same $C_{\infty}=0.76 \mathrm{~m} / \mathrm{s}$. Note that the value of $u_{*}$ for the model no. 1

278 has been selected to have the same crossing point with $C_{\infty}$ as model no. 3 , that is, $u_{*}=$ $2790.45 \mathrm{~cm}$.

280 The main drawback of models no. 2 and 3 is that both of them have been fitted with particular 281 measurements, thus, the values of the parameters for other conditions and values of $C_{\infty}$ are 282 unknown.

283 For the present work, the first model has been chosen because it is simple yet sufficiently 284 accurate. Furthermore, it can be applied to different values of $z_{0}$ and $C_{\infty}$.

285 In order to incorporate the boundary layer into the FEM model, the curve has been simplified 286 by breaking it down into a set of linear segments (visible on Figures 7 and 8). The crossing 287 point between the curve and $C_{\infty}$ is considered the limit of the boundary layer, which indicates 288 the thickness of the boundary layer.

\subsection{Data analysis}

291 In the present work, three analysis are made, the first one is a qualitative description of the 292 measurements for a single haul, in order to better understand the influence of the boundary 293 layer on the measured bridle's tensions. In the second one, a correlation between the measured 294 GS and WS for nearly all the hauls (this point will be also explained in this subsection) is 295 established. Finally, the measurements of tensions for nearly all the hauls are compared with 296 the numerical results for different boundary layers.

297 A clarification about the velocity is required, the relative velocity profile along the depth ws, 298 which determines the drag, is affected by the ground speed $G S$ and the sea current profile $c$ as 299 defined by Equation 16. The inclusion of the boundary layer in the sea current profile $c$ can 
change ws, for example, at depths close to the seabed. Consequently, the drag could increase

301 or decrease in comparison with no considering the boundary layer.

$302 w s=G S-c$

303 Figure 6 shows a diagram of velocity profiles. Different possible values of ground speed (GS)

304 are represented for the same value of WS, when the boat is with current (case a), without

305 current (case b) or against current (case c). Measured values are displayed as dashed green

306 line and the theoretic profiles are shown in black. The indicated values of the velocities will

307 be explained in Section 5.2. The velocity GS is constant with depth as the whole trawl is

308 being towed at a constant speed. The profile of the sea current $c$ can be approximated by the

309 classical boundary layer logarithmic curves (described later). The profile of ws with depth

310 was not quantified at sea; only measurements in the head line were recorded (WS). Between

311 the three situations (with, without current and against current, Figure 6), it can be observed

312 that the water speed close to the bottom increases when GS increases, even though the water

313 speed at the headline (WS) is nearly constant. Therefore, the drag close to the bottom

314 increases and consequently the bridle's tensions.

315 For the third analysis, Figures 7 and 8 show the boundary layer profiles used for the

316 simulation, when the boat is with current and against current, respectively. The depth of the

317 seabed that has been chosen is $56 \mathrm{~m}$, which is the mean of the depth of the hauls considered

318 in this study. As the type of soil and hydrodynamic regime are unknown, different values for

$319 z_{0}$ are assessed: $0.005 \mathrm{~cm}, 0.03 \mathrm{~cm}, 0.07 \mathrm{~cm}$ and $0.3 \mathrm{~cm}$ (from Soulsby (1983)). The different

320 roughness lengths deliver different shapes of the boundary layer. In Figure 7, it can be

321 observed that, as the $z_{0}$ increases, the thickness of the boundary layer also increases.

322 However, a thickness larger than the vertical opening of the trawl (3.5 $\mathrm{m}$ according to the 
$324 z_{0}=0.3 \mathrm{~cm}$ is about $9 \mathrm{~m}$, so this value is discarded from the analysis.

325 Moreover, in order to remark the effect of the boundary layer, we also have included the case 326 where there is no boundary layer. In this situation, the water speed is constant regardless of 327 the depth.

328 In summary, in the third analysis, for each value of the roughness length $(0.005 \mathrm{~cm}, 0.03 \mathrm{~cm}$ 329 and $0.07 \mathrm{~cm})$, three different situations are simulated, when the boat is with current $(W S=$ $3301.54 \mathrm{~m} / \mathrm{s}$ and $G S=2.09 \mathrm{~m} / \mathrm{s})$, without current $(W S=G S=1.59 \mathrm{~m} / \mathrm{s})$ and against current $(W S=$ $3311.65 \mathrm{~m} / \mathrm{s}$ and $G S=1.09 \mathrm{~m} / \mathrm{s}$. Besides, the case of no considering the boundary layer is taken 332 into account, resulting in 12 different simulations. The values of WS and GS will be explained 333 in subsection 5.2. The bottom and top bridle's tensions (FS and FI, respectively) are plotted in 334 function of the ground speed GS and compared with the measurements for nearly all the 335 hauls.

336 When analysing the measurements for all the hauls, the mean and the standard deviation are 337 evaluated as follows: for each haul considered in this study, the linear relation between the 338 bottom tension FI and the ground speed GS is calculated. For each GS, the bottom tension is 339 calculated by using the linear relations established for each haul; and then, from this set of 340 values, the mean bottom tension and the standard deviation are calculated. Consequently, for 341 each GS the mean bottom tension of all the hauls and the corresponding standard deviation 342 are available. The same method is applied to the top tension FS vs. ground speed GS.

343 The aim of this method is to avoid the variability of some parameters that are quite difficult to 344 control during the hauls, such as depth, sea state, weather conditions, etc... which can also 345 affect the bridle tensions. The measurements are analysed haul by haul, because, although 346 these parameters could present large variations between different hauls, they can be 
347 approximated as constant during each haul. The sea state and the weather can be considered in

348 the same conditions during the 3.5 hours that a haul lasts, on average. The depth of the seabed

349 can also be considered constant along the mean distance covered by the boat on each haul,

350 approximately $20 \mathrm{~km}$.

351 Regarding the hauls considered in the study,among the 37 hauls that were recorded, only the

352 hauls which present a large variation of the ground speed (standard deviation of the ground

353 speed larger than $0.2 \mathrm{~m} / \mathrm{s}$ ) are considered, because if the range of variation of $G S$ is not wide

354 enough, we can not evaluate the effect of the ground speed GS and extract any conclusions

355 from these data. The number of hauls that present a standard deviation of GS larger than 0.2

$356 \mathrm{~m} / \mathrm{s}$ is 23 . Therefore, only these 23 hauls are used in this analysis, resulting in 14 discarded

357 hauls. With this method we can accept that only the effect of GS on the bridle tension is

358 analysed, since the remaining parameters have been neutralized as much as possible.

359 5. Results

360 Analysis of a single haul

361 During the fishing performance on each haul, the boat followed a path, which was not always

362 straight. These changes in the trajectory were reflected in all of the measurements. Figures 9

363 to 13 show the measurements for haul 7. The following observations can also be applied to

364 the other hauls.

365 Figure 9 represents the trajectory followed by the boat in GPS coordinates. It can be observed

366 that the boat goes straight from the starting point $\mathbf{P}$ and then comes back following more or

367 less the same path. Figure 10 shows the ground speed (GS) and the water speed (WS) versus

368 haul duration. It can be observed that, while the water speed remains approximately constant

369 (except by the peak at $671.7 \mathrm{~h}$ ), the ground speed has a step at $671.7 \mathrm{~h}$, probably due to the

370 change of direction. This variation on the speed also has an effect on the tension in wires

371 (Figure 11), where an increment in the bottom bridle’s tension can be noted at $671.7 \mathrm{~h}$. 
372 Figures 12 and 13 plot the bottom bridle's tension (FI) versus the water speed (WS) and the

373 ground speed (GS), respectively. In Figure 12 there is a large variability in the bottom bridle's

374 tension while the water speed remains constant. In Figure 13 the points can be divided into

375 two groups because of the step in the ground speed; also, there is a corresponding increase in

376 tension.

377 The drag force is mostly determined by the contact with the bottom and by hydrodynamic

378 forces. Regarding the friction with the bottom, results from Pashen et al. (2000) obtained by 379 experimental campaigns revealed that the friction was approximately independent of the 380 towing speed. In this work we assume this approach, however, awareness should be taken into 381 account as Pashen et al. (2000) did not verified this result for different types of soil.

382 The second factor, the hydrodynamic forces, depends on the direction and magnitude of fluid 383 velocity relative to the object. Measurements reveal two relations worthy of investigation:

384 Firstly, according to the widely used formulation of Morrison, if the relative speed remains 385 constant the drag will also be constant. However, in Figure 12 there is notable variability in 386 the bottom tension while the measured values of the water speed (WS) are nearly constant.

387 Secondly, Figure 13 plots the bottom tension FI in function of the ground speed (GS) where 388 two groups of data can be appreciated. As the GS speed increases the tension also increases.

389 The consideration of the boundary layer can justify these two relations, since a variable 390 current profile can affect the drag close to the ground, as shown in Figure 6.

391 5.1. Analysis of the water speed and the ground speed

392 In this subsection, the values for GS and WS from the measurements used for the analysis

393 (showed in Figure 6) are explained). Figure 14 presents the water speed WS vs. the ground

394 speed GS. There is a small variation in water speed because the boat has been driven at a 395 constant power instead of a constant water speed. A linear relation can be established: 
397 When the boat is driven without current (case b), the water speed is equal to the ground speed,

398 according to the previous expression $W S=G S=1.59 \mathrm{~m} / \mathrm{s}$. For the states a) and c), the values 399 of the ground speed are $1.09 \mathrm{~m} / \mathrm{s}$ and $2.09 \mathrm{~m} / \mathrm{s}(1.59 \pm 0.5 \mathrm{~m} / \mathrm{s})$. This amplitude $( \pm 0.5 \mathrm{~m} / \mathrm{s})$ is 400 considered representative of the variation observed at sea (Figure 14) and is considered wide 401 enough to involve the schematic situations a) and b) from Figure 6, where the boat is with 402 current and against current. Then, the value of the water speed at the headline (WS) is deduced 403 through Equation 17 (1.65 m/s and $1.54 \mathrm{~m} / \mathrm{s}$ in Figure 14). With these values of GS and WS, 404 the water speed profiles ws are calculated by mean the Equation 16 and the model of the 405 boundary layer.

406 5.2. Comparison of numerical and experimental results for all hauls

407 The experimental results are compared with the numerical simulations including the boundary 408 layer. Figures 15 and 16 plot the measurements of all the considered hauls (represented as 409 points) as well as the results of the simulations (plotted as markers). The bottom tension (FI) 410 vs. ground speed (GS) is represented in Figure 15. Figure 16 displays the top tension (FS) vs. 411 ground speed (GS). In order to complement these figures, results are also reported in Tables 1 , 4122 and 3 . Table 1 shows the value of the bottom and top tension for all of the simulations.

413 Table 2 shows the slopes of the tension values vs. the ground speed obtained from the

414 measurements and the simulations for each value of $z_{0}$. The difference between the slopes

415 obtained by simulation and the slopes from the measurements is expressed as a relative error.

416 Table 3 shows the drag repartition of different components of the trawl when the boat is 417 without current.

418 In Figures 15 and 16, the line is the mean value of the bottom tension, and the dashed lines 419 below and above the line are the mean value plus or minus the standard deviation. This 420 method gives the following relations between bridle tension and ground speed: 
$421 \quad F I=5778.09( \pm 1334.16)+1196.82( \pm 713.19) G S$

$422 \quad F S=9996.39( \pm 2913.57)+1065.95( \pm 1697.13) G S$

423 The bottom tension measured at sea increases when the ground speed increases, as shown in

424 Figure 15. The case where there is no boundary layer (no BL) corresponds to the situation

425 where the whole trawl is affected by a constant water speed, which is taken at the headline

426 (WS). The simulation results from this case lead to a decrease in the bottom tension (Figure

427 15). This simulation does not fit the measurements, giving the highest value of the relative 428 error between the numerical and experimental slopes, that is $143 \%$. The simulations of the

429 case in which the boundary layer is considered demonstrate an increment in the bottom

430 tension, as shown in Figure 15. The best fitting corresponds to $z_{0}=0.03 \mathrm{~cm}$, which is

431 equivalent to a boundary layer with a thickness of $0.89 \mathrm{~m}$ (Figures 7 and 8), whose slope has

432 an error of $12 \%$ relative to the slope from the measurements.

433 The top tension measured at sea is approximately constant, regardless of the ground speed, as

434 shown in Figure 16. If the boundary layer is not considered, the simulation results do not fit

435 the data, as this leads to a decrease in the top tension. For the cases where the boundary layer

436 is included, the top tension varies from decreasing to increasing. The best fitting corresponds

437 to $z_{0}=0.03 \mathrm{~cm}$ with an error of $402 \%$ relative to the slope from the measurements, which is

438 coherent with the fitting of the bottom bridle's tension . Remark that the high relative errors

439 of the top tension are due to the small value of the experimental top tension slope.

\section{6. Discussion and conclusion}

441 The results for the haul 7 are coherent with the schema shown in Figure 6. The increment of

442 the bottom tension shown in Figure 11 at 671.7 h may be explained because the boat passed

443 from towing against current (case c) to towing with current (case a), the water speed

444 increases close to the bottom (and therefore the drag) although the water speed measured at 445 the headline is nearly constant. 
446 To support this qualitative analysis, the comparison of the third analysis reveals that the 447 inclusion of a model of the boundary layer improves the fitting with the measurements, 448 causing a $91 \%$ of reduction of the relative error of the slopes with respect of no considering 449 the boundary layer in the bottom tension and a $71 \%$ of reduction in the top tension.

450 According to our measurements at sea, the bottom tension increases with ground speed while

451 the top tension remains nearly constant and consequently, the influence of the boundary layer 452 is much more notable in the bottom tension than in the top tension. Simulation results (Table 453 1) support this statement but it is possible that another trawl or rigging could lead to another 454 conclusion (modification of bridle top tension).

455 It can also be seen that when the ground speed (GS) increases, the bottom bridle's tension 456 increases (Figure 15), and, simultaneously, the water speed (WS) decreases (Figure 14). This 457 relation between the water speed and the ground speed occurs because the boat is driven at a 458 constant rate of consumption ( $107 \mathrm{l} / \mathrm{h}$ of fuel). This constant rate of consumption leads to a 459 constant amount of power required by the gear, as the efficiency of the engine and propeller 460 are likely constant for this small variation of water speed $(1.54 \mathrm{~m} / \mathrm{s}$ to $1.65 \mathrm{~m} / \mathrm{s})$.

461 Consequently, the increment of bottom bridle tension is probably associated to an increment 462 of drag, which leads to a decrease in towing speed (or water speed) in order to maintain 463 consistent power.

464 However, this model has some weaknesses worthy of improvement:

465 - The selected model of the boundary layer is quite basic. The choice of this model is also 466 subject to discussion and could be replaced by more detailed models such as the curves 467 developed by Perlin et al.(2005) or Sanford and Lien (1999).

468 - The numerical model used for the contact with the bottom does not discern between friction 469 and bottom wearing which could influence the bottom tension. The type of soil is neither 
470 included in this model. Table 3 shows that the drag forces due to the contact with the seabed

471 are about $18 \%$ of the total drag, a more accurate model which includes the influence of the

472 type and disposition of the soil could improve this assessment.

473 - The hydrodynamic drag is calculated as the sum of the drag on all components. In the case

474 of netting perpendicular to flow, this assumption is probably acceptable. In the case of netting

475 parallel to flow, this assumption is debatable, as the last twines are in the shadow of the first 476 ones. This point probably magnifies the drag of netting parallel to flow, which is the case of 477 netting situated in the trawl belly (the piece of netting close to the bottom). Consequently, it is 478 possible that a more accurate drag model might lead to a thicker boundary layer, which would 479 result in more netting being affected.

480 -The boundary layer was not included in the calculation of the hydrodynamic drag of the 481 catch and doors (where the relative velocity profile is considered as constant). We consider 482 that the error introduced by this hypothesis could affect slightly the results since these forces 483 take about 35\% of the total drag (Table 3) which is smaller than the drag from netting and 484 wires (46\% of the total drag in Table 3 ).

485 -The boundary layer also requires experimental validation, it is necessary to check if the value 486 of $\mathrm{z}_{0}$ that best fits the measurements matches with the type of soil and hydrodynamic regime 487 of the sea trials.

488 - The FEM model combined with the Newton Raphson Method requires the evaluation of the

489 Jacobian matrix. In this work, the boundary layer equation has not been included in the

490 Jacobian matrix, in order to simplify its analytical expression. The inclusion of the boundary

491 layer equation in the Jacobian matrix would improve the computational efficiency of the

492 Newton Raphson Method.

493 Moreover, the experimental data have their limitations since the sea trials were designed with 494 a different proposal than the aim of this paper. It would be better to include sensors at 
495 different depths of the trawl, in order to measure the relative water speed profile ws and taking

496 measurements of the friction with the seabed and samples of the soil. In addition, it is

497 necessary to validate experimentally the drag repartition table.

\section{7. Acknowledgements}

499 The authors want to thank the Wacogne family, the crew of the boat “Arc-en-ciel”, the French

500 ministry of Fisheries, and the European funds for fisheries that have contributed in order to

501 carry out this study.

502

503

8. References

504 - Aoustin Y., 1990, Courants de maree: caracterisation de la couche limite de fond et

505 indications sur la validite des modeles, IFREMER report, December 1990.

506 - Coles, R. G., 1979, Catch size and behaviour species of preadults of penaeid prawn as

507 influenced current direction, trawl alignment, of three by tidal and day and night period , J.

508 exp. mar. Biol. Ecol., Volume 38, Pages 247- 260.

509 - Ferro R.S.T., van Marlen B., Hansen K.E., 1996, An empirical velocity scale relation for

510 modelling a design of large mesh pelagic trawl, Fisheries Research, Volume 28, Issue 2,

511 September 1996, Pages 197-230.

512 - Ivanović, A., Neilson R.D., O'Neill, F.G., 2011, Physical modeling for underwater flexible

513 systems dynamic simulation, Ocean Engineering, Volume 38 (7), Pages 925-933.

514 - Lee, C.-W., Lee J.-H., Cha B.-J., Kim H.-Y., Lee, J.-H., 2005, Physical modeling for

515 underwater flexible systems dynamic simulation, Ocean Engineering, Volume 32, Issues 3-4,

516 Pages 331-347.

517 - Park, H.H., 2007, A method for estimating the gear shape of a mid-water trawl, Ocean 518 Engineering, Volume 34 (2007), Pages 470-478. 
- Perlin A., Moum J.N., Klymak J.M., Levine M.D., Boyd T., Kosro P.M. , 2005, A modified

520 law-of-the-wall applied to oceanic bottom boundary layers, Journal of Geophysical Research,

521 Vol. 110, C10S10, September 2005.

522 - Pashen M., Ritcher U., Köpnick W., 2000, Trapese Trawl Penetration in the Seabed, Final

523 Report, Contract No. 96-006, Rostok, 2000-4, Research project of the European Community,

524 Directorate General XIV-Fisheries.

525 - Priour, D., 2003. Analysis of nets with hexagonal mesh using triangular elements,

526 International Journal for Numerical Methods in Engineering, Volume 56, Issue 12, 28, Pages

$527 \quad 1721-1733$.

528 - Priour, D. 2009. Numerical optimisation of trawls design to improve their energy efficiency,

529 Fisheries Researc, 98 (2009) 40-50.

530 - Priour, D., 2012. Rapport final du projet EFFICHALUT , 01 - 2012 - Rapport

531 DCB/RDT/HO/R12-001.

532 - Priour, D., 2013a. A finite element method for netting. Application to fish cages and fishing

533 gear. ISBN 978-94-007-6843-7. Springer Briefs in Environmental Science. Springer.

534 - Priour, D., 2013b. The effect of catch weight on trawl behaviour, Proceedings of DEMAT

5352013 Conference, Contributions on the theory of fishing gears and related marine systems.

536 Vol. 8, Rostok, October 2013, Pages 3-12.

537 - Sala, A., De Carlo, F.,Buglioni, G., Lucchetti, A., 2011, Energy performance evaluation of

538 fishing vessels by fuel mass flow measuring system, Ocean Engineering, Volume 38, Issues

539 5-6, April 2011, Pages 804-809.

540 - Sanford T.B., Lien R-C., 1999, Turbulent properties in a homogeneous tidal bottom

541 boundary layer, Journal of Geophysical Research, Vol. 104, No, C1, January 1999, Pages

$542 \quad 1245-1257$. 
543 - Somerton, D. A. , Weinberg K. L , 2001, The affect of speed through the water on footrope

544 contact of a survey trawl, Fisheries Research, Volume 53, Issue 1, September 2001, Pages 1754524.

546 - Soulsby R.L., 1983, The bottom boundary layer of shelf seas. In: Physical Oceanography of

547 coastal and shelf seas edited by B. JOHNS, Elsevier Oceanography Series, Pages 189-266.

548 - von Szalay, P.G. , Somerton , D. A. , 2005, The effect of net spread on the capture efficiency

549 of a demersal survey trawl used in the eastern Bering Sea , Fisheries Research, Volume 74,

550 Pages 86-95.

551 - Takagi, T. , Shimizu, T. , Suzuki, K. , Hiraishi, T., Yamamoto, K., 2003. Validity and layout

552 of "NaLA": a net configuration and loading analysis system, Fisheries Research, Volume 66,

553 Pages 235-243.

554 - Tsukrov, I., Eroshkin, O. Fredriksson, D. Swift M.R. and Celikkol B., 2003. Finite element 555 modeling of net panels using a consistent net element, Ocean Engineering Volume 30, Issue 556 2, February 2003, Pages 251-270.

557 - Ward J.N., Ferro R.S.T., 1993, A comparison of one-tenth and full-scale measurements of 558 the drag and geometry of a pelagic trawl, Fisheries Research, Volume 17, Issues 3-4, August 559 1993, Pages 311-331.

560 - Weinberg , K.L. , Somerton, D.A., Munro, P.T., 2002, The effect of trawl speed on the 561 footrope capture efficiency of a survey trawl, Fisheries Research, Volume 58, Pages 303-313. 
563 Table 1: Results from the simulation of bottom bridles tension (FI) and top bridles tension

564 (FS) : when the boat goes with current, without current and against current for the different

565 values of the roughness length $z_{0}$, and in case of no boundary layer.

\begin{tabular}{ccccccc}
\hline & \multicolumn{2}{c}{ Boat with current } & \multicolumn{2}{c}{ No current } & \multicolumn{2}{c}{ Against current } \\
\hline $\mathbf{z}_{\mathbf{0}}$ & $\boldsymbol{F I}$ & $\boldsymbol{F S}$ & $\boldsymbol{F I}$ & $\boldsymbol{F S}$ & $\boldsymbol{F I}$ & $\boldsymbol{F S}$ \\
$\mathbf{( c m )}$ & $\mathbf{( N )}$ & $\mathbf{( N )}$ & $\mathbf{( N )}$ & $\mathbf{( N )}$ & $\mathbf{( N )}$ & $\mathbf{( N )}$ \\
\hline $\mathbf{0 . 0 7}$ & 8259.04 & 10538.98 & 7228.01 & 10125.98 & 6324.02 & 9960.98 \\
\hline $\mathbf{0 . 0 3}$ & 7901.96 & 10099.98 & 7228.01 & 10125.98 & 6558.97 & 10419.99 \\
\hline $\mathbf{0 . 0 0 5}$ & 7171.99 & 9913.99 & 7228.01 & 10125.98 & 7229.97 & 10595.00 \\
\hline No BL & 6948.91 & 9293.01 & 7228.01 & 10125.98 & 7461.98 & 10673.97 \\
\hline
\end{tabular}

567 Table 2: Slopes of the linear relation between the tension (top and bottom bridles ) and the

568 ground speed. These slopes are obtained by simulation for different values of the roughness

569 length, and also when there is no consideration of boundary layer and by measurements. The

570 difference between the numerical and experimental slopes is quantified through the error

571 relative to the experimental slope.

\begin{tabular}{|c|c|c|c|c|}
\hline $\begin{array}{c}Z_{0} \\
(\mathbf{c m})\end{array}$ & \multicolumn{2}{|c|}{$\begin{array}{l}\text { Slope } F I \\
(\mathrm{~N} /(\mathrm{m} / \mathrm{s}))\end{array}$} & \multicolumn{2}{|c|}{$\begin{array}{l}\text { Slope } F S \\
(\mathrm{~N} /(\mathrm{m} / \mathrm{s}))\end{array}$} \\
\hline \multirow[t]{2}{*}{ Measurements } & \multicolumn{2}{|c|}{$1196.82 \pm 713.19$} & \multicolumn{2}{|c|}{$105.95 \pm 1697.13$} \\
\hline & Slope & Relative error (\%) & Slope & Relative error (\%) \\
\hline 0.07 & 1935.02 & 62 & 578.01 & 446 \\
\hline 0.03 & 1342.99 & 12 & -320.00 & 402 \\
\hline 0.005 & -57.98 & 105 & -681.01 & 743 \\
\hline No BL & -512.96 & 143 & -1381.05 & 1404 \\
\hline
\end{tabular}

574 Table 3: Drag repartition (\%) of the different components obtained by simulation when the

575 boat is without current. 


\begin{tabular}{cl}
\hline Drag Repartition & $\%$ \\
\hline Friction with the bottom & 18 \\
\hline Drag from catch & 10 \\
\hline Hydro. drag from wires & 18 \\
\hline Hydro. drag from netting & 28 \\
\hline Hydro drag from doors & 26 \\
\hline
\end{tabular}


LIST OF FIGURES

577 Figure 1 : Design of the trawl. The mesh size and twine diameter are on the left. The panels 578 size is noted.

580 Figure 2: Design of the rigging. The top bridle is fixed to the warp.

582 Figure 3: Position of the sensors on the trawl. The positions of the sensors are marked as red 583 dots.

Figure 4: Scheme of a classical bottom boundary layer, represented as depth in function of the flow velocity $z(c)$. The bed sublayer, logarithmic sublayer and the outer sublayer are noted.

Figure 5: Comparison between three models of the boundary layer: the classical logarithmic law-of-the-wall, the lower and upper curves and the modified law-of-the-wall. The freestream velocity $C_{\infty}$ is also indicated.

592 Figure 6: Scheme of velocity profiles (velocity with depth) of different values of the ground 593 speed GS for the same value of the water speed $W S$ at the headline. The sea current profile is 594 represented as $c$.In the case a) the boat moves with current, and in b) the boat goes against current.

597 Figure 7: Water speed profile ws for different $z_{0}$ used in the simulations when the boat goes 598 with current. The thickness of the boundary layer, considered as the crossing point of the 599 logarithmic curve with $C_{\infty}$ is indicated in the legend. Also, the measurements WS and GS are 600 plotted. 
602 Figure 8: Water speed profile ws for different $z_{0}$ when the boat goes against current. The

603 thickness of the boundary layer, considered as the crossing point of the logarithmic curve with

$604 C_{\infty}$ is indicated in the legend. Also, the measurements WS and GS are plotted.

605

606 Figure 9: Trajectory followed by the boat represented in North and East GPS coordinates 607 during haul 7.

608

609 Figure 10: Ground speed (GS) and water speed (WS) versus haul time for haul 7.

611 Figure 11: Measurements of bottom (FI) and top (FS) bridle tension versus haul time for haul 6127.

614 Figure 12: Measurements of bottom tension versus water speed (WS) for haul 7.

616 Figure 13: Measurements of bottom bridles tension versus ground speed (GS) for haul 7.

618 Figure 14: Measurements of the water speed (WS) vs. the ground speed (GS) for all the hauls.

619 A linear relation can be established. The 3 pairs of values for ground speed and water speed

$620(1.09 \mathrm{~m} / \mathrm{s}, 1.65 \mathrm{~m} / \mathrm{s}),(1.59 \mathrm{~m} / \mathrm{s}, 1.59 \mathrm{~m} / \mathrm{s})$ and $(2.09 \mathrm{~m} / \mathrm{s}, 1.65 \mathrm{~m} / \mathrm{s})$ correspond to the 3 states

621 when the boat is against current, with no current and with current, respectively.

623 Figure 15: Bottom bridles tension FI vs. ground speed GS for all the hauls. The

624 measurements are plotted as points, the line represents the mean variation and the curves

625 represents the standard deviation. The simulation results are displayed as markers. 
627 Figure 16: Top bridles tension FS vs. ground speed GS for all the hauls. The measurements

628 are plotted as points, the line represents the mean variation and the curves represents the 629 standard deviation .The simulation results are displayed as markers. 
630 

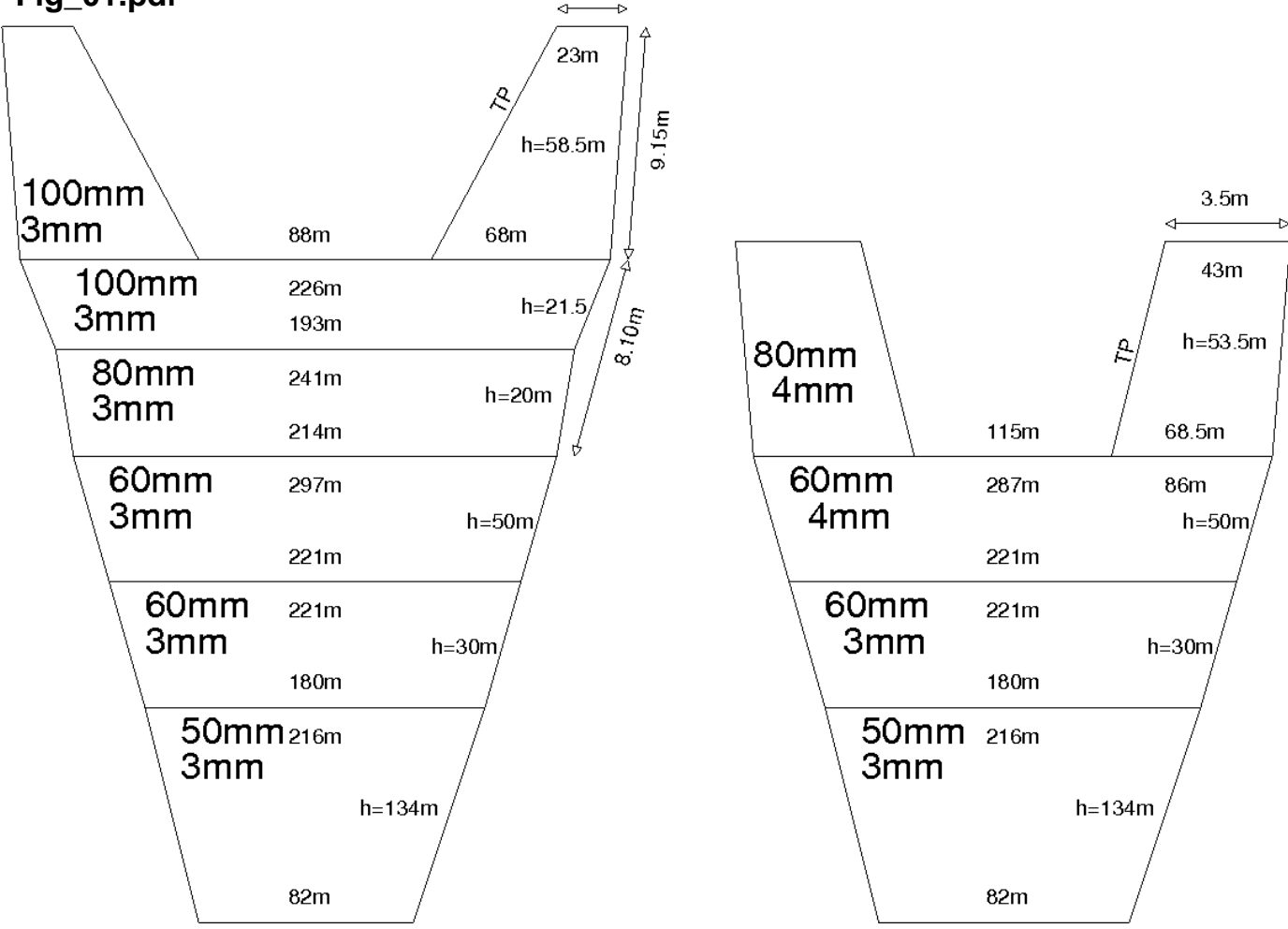
Figin02.pdf net 


\section{Fig_03.pdf}

Vertical tension and water speed

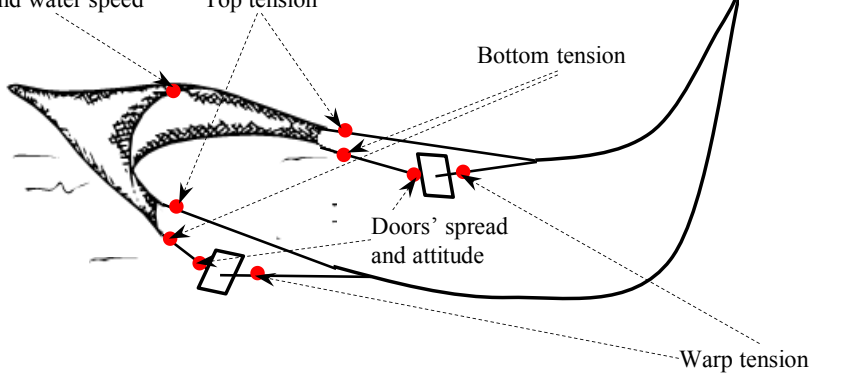




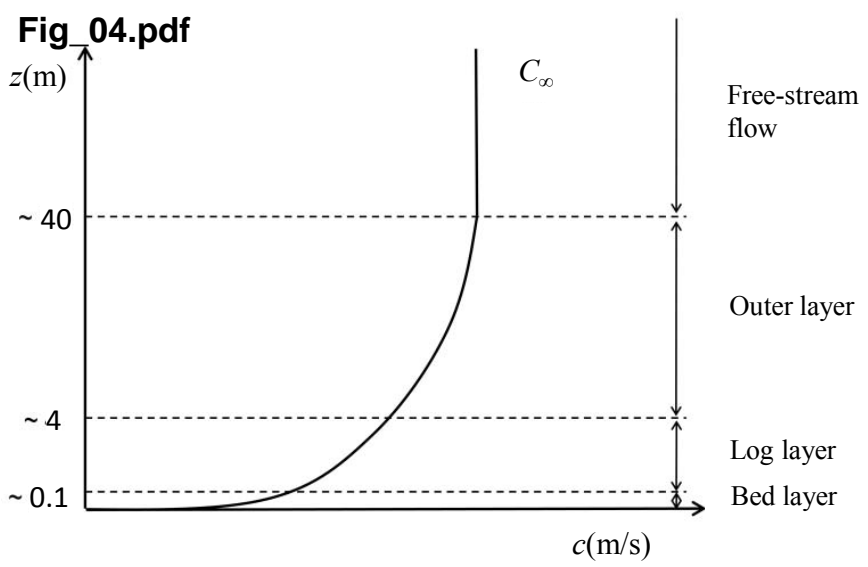


a)

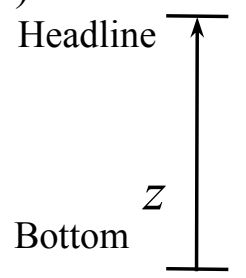

b)

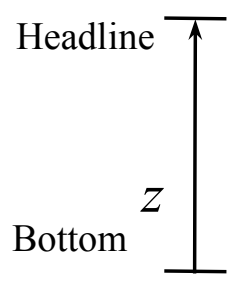

c)

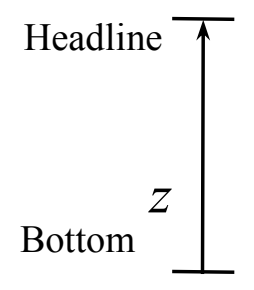

$G S$

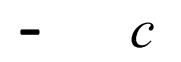

$=W S$

\section{$2.09 \mathrm{~m} / \mathrm{s}$}

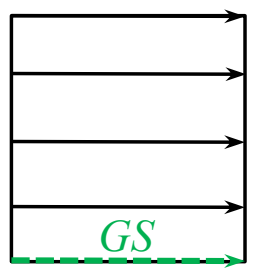

$1.59 \mathrm{~m} / \mathrm{s}$

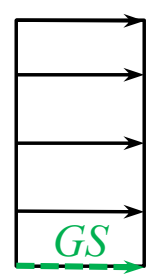

$1.09 \mathrm{~m} / \mathrm{s}$

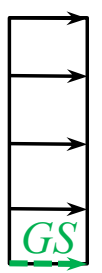

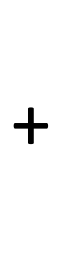

$1.54 \mathrm{~m} / \mathrm{s}$

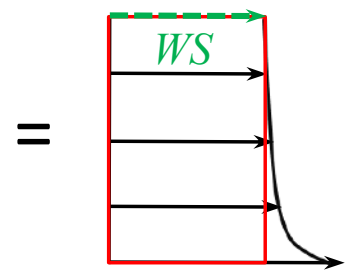

$1.59 \mathrm{~m} / \mathrm{s}$

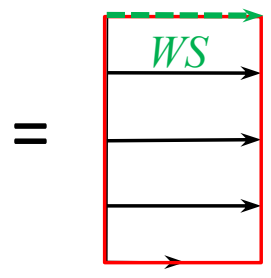

$1.65 \mathrm{~m} / \mathrm{s}$
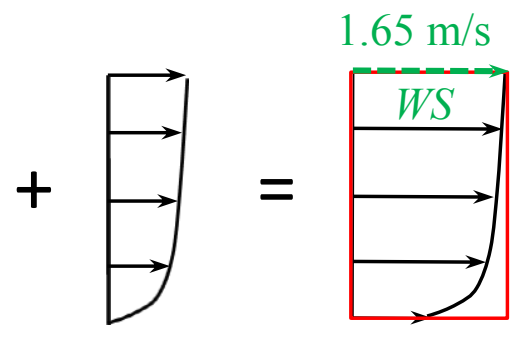
Fig_07.pdBoat with current. $G S=2.09 \mathrm{~m} / \mathrm{s}, W S=1.54 \mathrm{~m} / \mathrm{s} \quad \mathrm{m}$

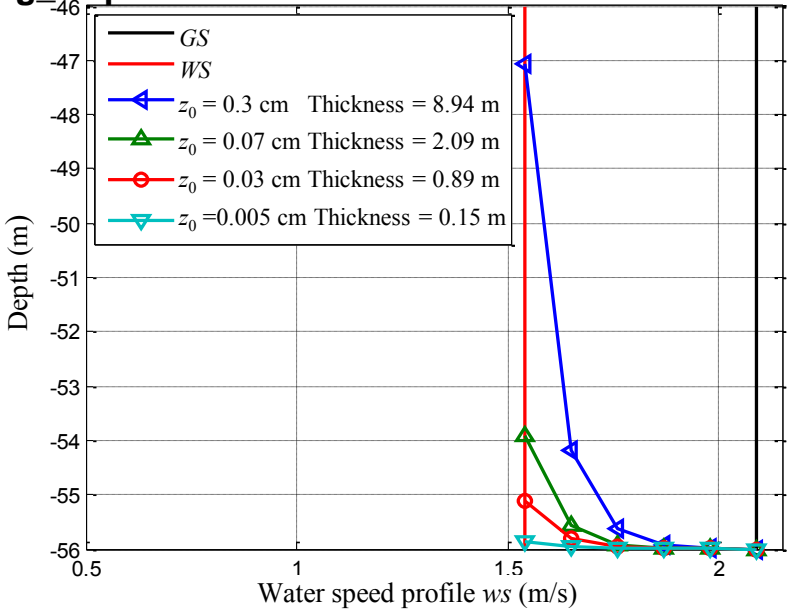


Fig_08.pdfoat against current. $G S=1.09 \mathrm{~m} / \mathrm{s}, W S=1.65 \mathrm{~m} / \mathrm{s}$

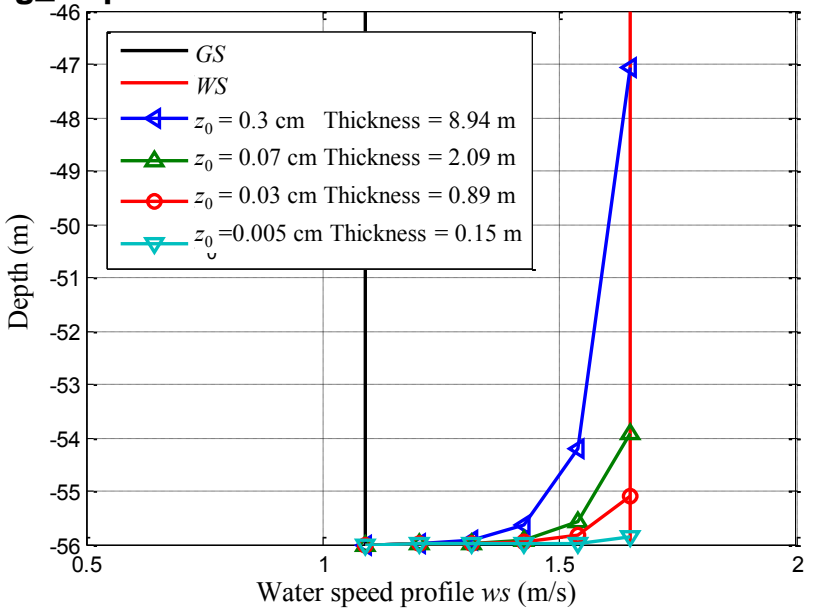




\section{$\mathrm{Fig}_{5}$ 09.pdf}

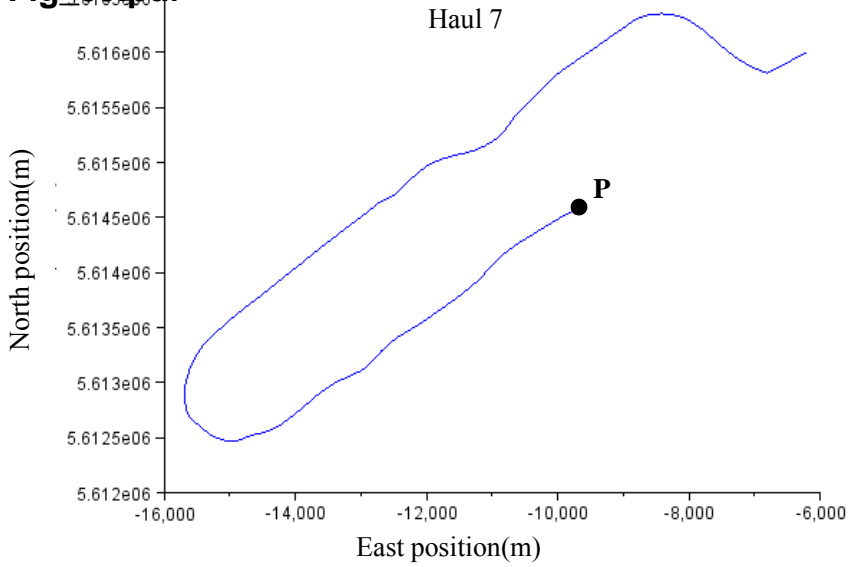


Fig_10.pdf

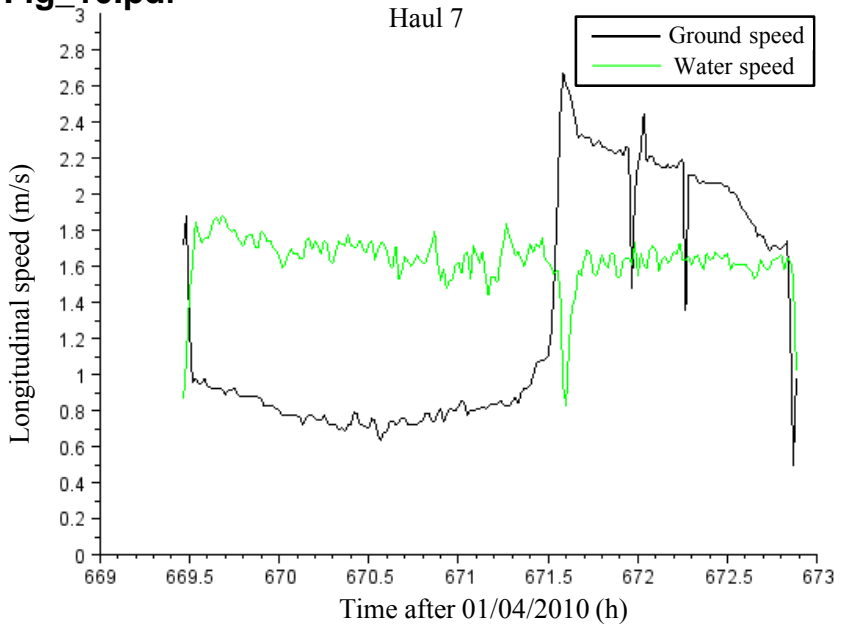


Fig_11.pdf

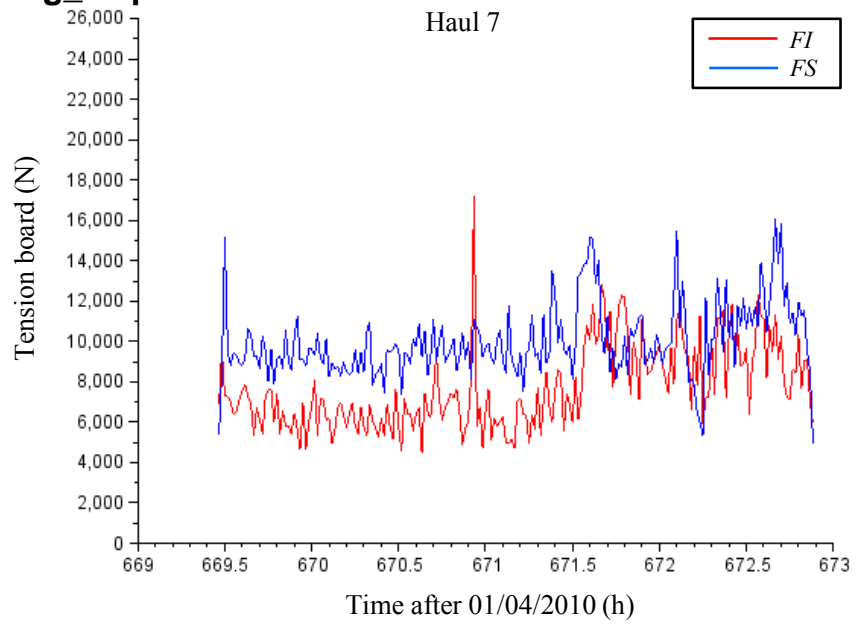




\section{$\mathrm{Fig}_{2 \theta, 000.12 \mathrm{pdf}}$}

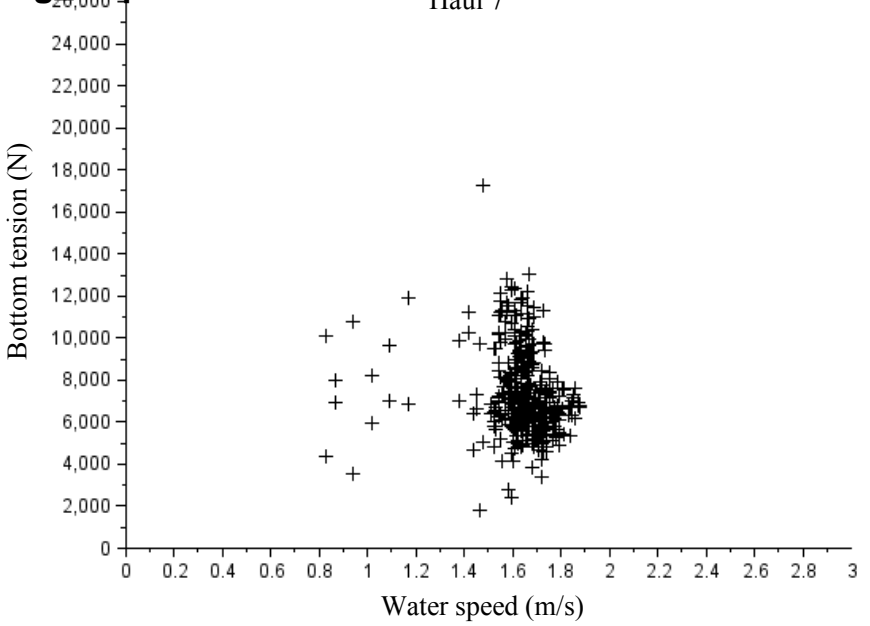




\section{Fig $_{26,000} 13 . p d f$}

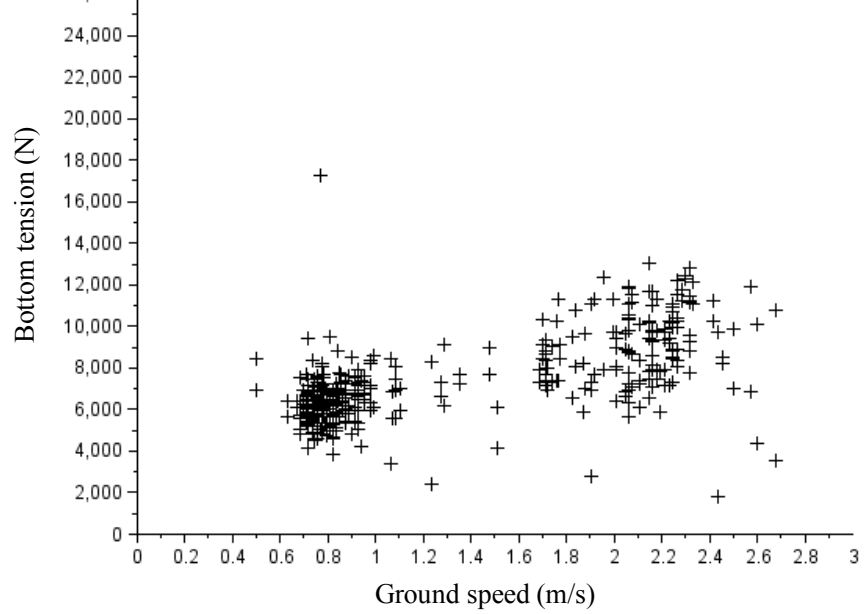




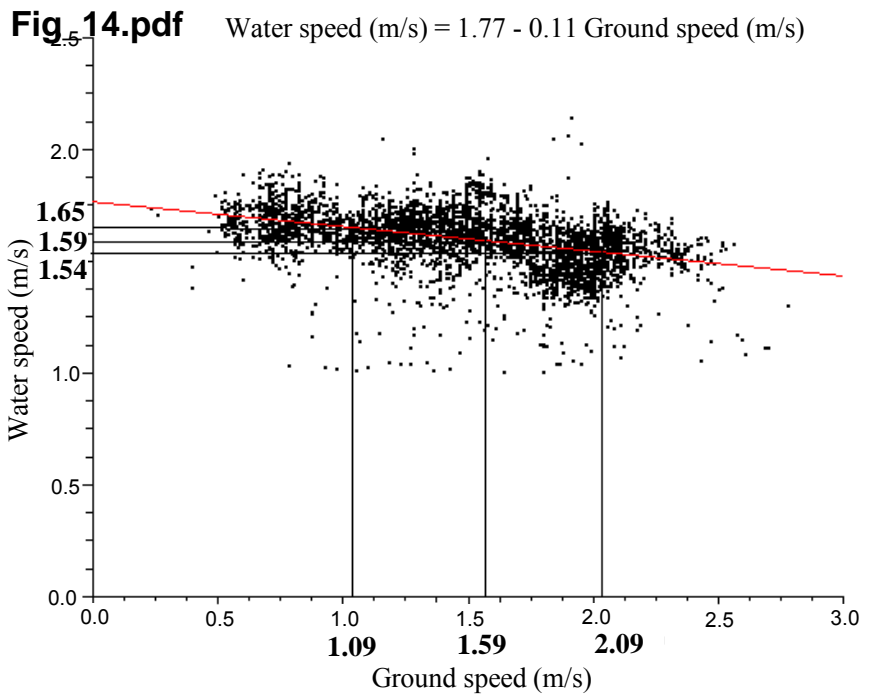


